\title{
Realising sexual and reproductive health and rights of adolescent girls and young women living in slums in Uganda: a qualitative study
}

\author{
Majel McGranahan ${ }^{1 *} \mathbb{0}$, Elizabeth Bruno-McClung ${ }^{1}$, Joselyn Nakyeyune ${ }^{2}$, Derrick Aaron Nsibirwa², \\ Christopher Baguma², Christopher Ogwang ${ }^{2}$, Francis Serunjogi², Judith Nakalembe², Marianna Kayaga², \\ Sharifah Sekalala ${ }^{3}$ and Oyinlola Oyebode ${ }^{1}$
}

\begin{abstract}
Background: Sexual and reproductive health and rights are critical entitlements best supported through human rights-based approaches empowering rights-holders to claim their rights and duty bearers to fulfil their obligations. Implementing these requires information on the current needs and challenges faced by those seeking to claim their sexual and reproductive health and rights. We aimed to identify the underlying factors influencing the realisation of sexual and reproductive health and rights for adolescent girls and young women living Ugandan slums by: (1) exploring the role of relevant service providers and stakeholders; and (2) uncovering knowledge and gaps in protecting adolescent girls' and young women's sexual and reproductive health and rights.
\end{abstract}

Methods: Qualitative data were collected through focus groups and interviews focused on current knowledge, behaviours and attitudes towards sexual and reproductive health and rights among adolescent girls and young women, service providers and stakeholders. Data were analysed thematically using NVivo software. Ten in-depth interviews were conducted with key informants; two focus groups were held with adolescent girls and young women living in two slums in Uganda (21 participants in total); and three focus groups were held with community leaders, service providers, teachers and parents (30 participants in total).

Results: Adolescent girls and young women lacked information regarding their sexual health, services available, and redress mechanisms for rights violations. Formal sources of information were frequently inaccessible. Family members were sometimes the source of rights violations, and informal methods of redressing rights were often sought. Stigma and fear were common features both in healthcare and in the pursuit of formal justice, with duty-bearers habitually breaking confidentiality. Education and training were the predominant suggestions offered for change.

Conclusions: Adolescent girls and young women continue to face obstacles in achieving their full sexual and reproductive health and rights. Targeted interventions for the realisation of adolescent girls' and young women's sexual and reproductive health and rights can address underlying causes and positively shift attitudes to promote health.

*Correspondence: majel.mcgranahan@warwick.ac.uk

${ }^{1}$ University of Warwick Medical School, Medical School Building, Coventry, UK

Full list of author information is available at the end of the article permits use, sharing, adaptation, distribution and reproduction in any medium or format, as long as you give appropriate credit to the original author(s) and the source, provide a link to the Creative Commons licence, and indicate if changes were made. The images or other third party material in this article are included in the article's Creative Commons licence, unless indicated otherwise in a credit line to the material. If material is not included in the article's Creative Commons licence and your intended use is not permitted by statutory regulation or exceeds the permitted use, you will need to obtain permission directly from the copyright holder. To view a copy of this licence, visit http://creativecommons.org/licenses/by/4.0/. The Creative Commons Public Domain Dedication waiver (http://creativeco mmons.org/publicdomain/zero/1.0/) applies to the data made available in this article, unless otherwise stated in a credit line to the data. 


\section{Plain Language Summary}

Every woman is entitled to good sexual and reproductive health. This involves being free from sexually transmitted infections, gender-based violence and maternal mortality, and able to access essential health services. In low and middle-income countries, adolescents comprise a fifth of the population, yet their sexual and reproductive health needs are often overlooked. Adolescent girls and young women are more likely to experience gender-based violence, sexually transmitted infections and poor access to sexual and reproductive health services. Those living in slums have even worse outcomes, but little evidence exists regarding the opportunities and barriers to improving sexual and reproductive health among adolescent girls and young women in a slum setting.

In this study, we conducted focus groups and interviews with 21 adolescent girls and young women living in two Ugandan slums, 10 individuals with an essential role, for example, at state level, as well as 30 other stakeholders including healthcare workers, teachers, parents, district leaders and community support officers working with adolescent girls and young women.

Results indicate that adolescent girls and young women lack information regarding their sexual health, what services are available and who and where to go if they experience violations such as sexual assault. In instances of sexual assault, fear and stigma prevented adolescent girls and young women from going to the police, and instead disputes were handled informally between families.

Participants in our focus groups and interviews felt that education and training were needed, and that health services need to improve. Interventions are necessary to improve adolescent girls' and young women's sexual and reproductive health in this setting.

Keywords: Sexual health, Reproductive rights, HIV, Jurisprudence, Patient advocacy, Reproductive Health

\section{Introduction}

Sexual and reproductive health and rights (SRHR) are crucial entitlements relating to women and girls' sexual and reproductive health [1]. These rights address the prevention of sexually transmitted diseases, including HIV, gender-based violence, maternal mortality and provision of essential health services [2-4]. Since the International Conference on Population and Development (1994) and the Beijing Platform for Action (1995), national SRHR policies have been demonstrated to support societies and contribute to a country's wealth $[2,3,5,6]$. The importance of SRHR is further underscored by section 5.6 of Sustainable Development Goal 5, dedicated to achieving SRHR for all [7].

Human rights-based approaches (HRBA), by emphasizing rights over needs, have become the focus of sustainable strategies for change $[5,8,9]$. The basic principles of HRBA include empowerment of rights-holders and duty-bearers (those responsible for protecting and enacting human rights), non-discrimination, open participation, accountability, and defined and established linkages between rights-holders and duty-bearers [5, 8]. For sexual and reproductive health, HRBA empower women to claim their rights and duty-bearers to fulfil their obligations $[8,10]$. By focusing on non-discrimination, HRBA also specifically consider those who are vulnerable, marginalized and discriminated against $[8,10]$, giving agency to the less powerful in society. Achieving these principles requires coordinated, multi-sectorial approaches, based on an analytical understanding of the needs of groups, available resources and challenges [11, 12].

Adolescents and emerging adults aged 15-24 comprise around a fifth of the population in low and middleincome countries (LMICs) [13], yet their needs are often overlooked and, particularly regarding sexual and reproductive health, underfunded $[2,6,14]$. In Uganda, teenage pregnancy rates are high, with one in four women aged 15-19 giving birth [15]. Adolescent girls and young women (AGYW) experience higher risks of gender-based violence, a disproportionate likelihood of sexually transmitted diseases, and frequently lack access to sexual and reproductive health services $[2,6,16]$. For AGYW living in urban slums, their visibility is reduced further by the double vulnerability of age and poverty [17].

Previous studies considering SRHR of women in LMICs have focused predominantly on sex workers, or maternity settings [18] A recent scoping review identified no qualitative evidence regarding sexual and reproductive health challenges among young people living in slums in Uganda, and limited qualitative evidence in the rest of Sub-Saharan Africa [17]. A cross-sectional study undertaken among 13-24 year olds in Makindye and Nakawa Divisions of Kampala, Uganda, identified sexual abuse a significant issue among participants, but the underlying facilitators and barriers were not explored [19].

There remains a need for studies focusing on AGYW, regardless of parity or engagement in sex work. This 
study aimed to explore the underlying factors impacting on the realisation of SRHR of AGYW living in slums in Wakiso District, Uganda.

\section{Methods}

In-depth interviews and focus groups were conducted in Wakiso District, Uganda, between February-August 2019. Qualitative data were collected regarding knowledge, attitudes and experiences of SRHR of AGYW living within slums. Kibwa and Kileku slums were selected as both are unplanned settlements representing established (Kibwa) and emerging (Kileku) slums whose semi-permanent population is known locally to face overcrowding, unhygienic conditions and high levels of violence and sexual crimes.

Two focus groups (one each in Kileku and Kibwa) were held with AGYW aged 14-23 years resident in either slum, recruited through established community connections. There were no exclusion criteria as a wide range of life-experiences were sought. Invitations to participate were by phone or verbal invitation. Focus groups were limited to an hour, during daytime, in private and accessible locations.

Ten 1:1 in-depth interviews were held with key informants including state and non-state actors (Table 1). Purposive sampling, with assistance from the Wakiso
District community development officer, was used to select participants based on their essential role in realising AGYW's SRHR. Participants were invited to participate by telephone.

Three focus groups were held with stakeholders, selected for their obligations to SRHR for AGYW (Table 1). Purposive sampling, with assistance from the district officer for health, and snowball sampling were used. Invitations were by telephone, email and letters. Groups were held in private spaces separate to working environments.

Participants gave written informed consent. Participants under 18 years who were unmarried required a caregiver's consent, unless pregnant.

Individuals who participated in focus groups were each given a number to identify themselves with (between 1 and 11), so individual's names were not used in recordings. No prior relationship existed between research team members and participants. Ethics committees in the UK and Uganda approved the study design.

\section{Data collection}

Interview and focus group topic guides were developed by members of Center for Health, Human Rights and Development (CEHURD), Uganda and University of Warwick, UK (see Additional files 1, 2 and 3).

Table 1 Study participants

\begin{tabular}{|c|c|c|c|}
\hline & Description & Kibwa or Kileku & Description of facilitator \\
\hline Focus Group 1 & $\begin{array}{l}10 \text { participants: } \\
\text { Female } \\
\text { Aged } 14-23 \text { years }\end{array}$ & Living in Kibwa slum & $\begin{array}{l}2 \times \text { facilitators } \\
2 \times \text { note takers }\end{array}$ \\
\hline Focus Group 2 & $\begin{array}{l}11 \text { participants: } \\
\text { Female } \\
\text { Aged } 16-20 \text { years }\end{array}$ & Living in Kileku slum & $\begin{array}{l}2 \times \text { facilitators } \\
2 \times \text { note takers }\end{array}$ \\
\hline Focus Group 3 & $\begin{array}{l}10 \text { participants: } \\
\text { Male and female } \\
\text { Local leaders } \\
\text { Local chairperson } \\
\text { Youth council representatives }\end{array}$ & Working in Kileku slum & $\begin{array}{l}1 \times \text { facilitator } \\
2 \times \text { note takers }\end{array}$ \\
\hline Focus Group 4 & $\begin{array}{l}10 \text { participants: } \\
\text { Male and female } \\
\text { Local leaders } \\
\text { Local chairperson } \\
\text { Youth council representatives }\end{array}$ & Working in Kibwa slum & $\begin{array}{l}1 \times \text { facilitator } \\
2 \times \text { note takers }\end{array}$ \\
\hline Focus Group 5 & $\begin{array}{l}10 \text { participants: } \\
\text { Male and female } \\
\text { Health workers (Public hospital) } \\
\text { Pharmacists (Private) } \\
\text { School teachers } \\
\text { Parents }\end{array}$ & Working in Kibwa slum & $\begin{array}{l}1 \times \text { facilitator } \\
2 \times \text { note takers }\end{array}$ \\
\hline $\begin{array}{l}\text { One to one interviews } \\
\qquad(\times 10)\end{array}$ & $\begin{array}{l}10 \text { participants: } \\
\text { Male and female } \\
3 \text { district leaders } \\
7 \text { staff from community-based organisations ( } 3 \text { community } \\
\text { outreach personnel and } 4 \text { team leaders) }\end{array}$ & $\begin{array}{l}\text { Working in Kibwa and/or Kileku } \\
\text { slums }\end{array}$ & 1 interviewer per participant \\
\hline
\end{tabular}


Trained researchers from CEHURD with qualitative research experience facilitated each focus group. Two additional CEHURD members wrote reflective notes. Focus groups were held in Luganda, with English as required.

Data were recorded, transcribed, translated and checked for accuracy by members of CEHURD. Triangulation with reflective notes was undertaken to reduce researcher bias.

\section{Data analysis}

Data were coded by members of CEHURD (DAN, JN, FA) and University of Warwick (MM, EB-M) using NVIVO with coding decisions discussed with a third University of Warwick team member (OO). Transcripts were thematically analysed using simultaneous inductive and deductive approaches with emerging themes compared within and across transcripts. Disputes were handled through team discussions and consensus.

Findings were reported following the Standards for Reporting Qualitative Research [20].

\section{Patient and public involvement}

Patients and/or public were not involved in the design, recruitment, conduct, or reporting of this study.

\section{Results}

Of 61 people invited to take part in the study, none declined. Table 1 describes the participant characteristics. AGYW included in the study were aged 14-23 years; six participants were aged 14-17 years, eleven were aged $18-20$ years and four were aged $21-23$ years. Table 2 outlines the identified themes and sub-themes. Additional file 4 includes examples of illustrative quotes for each sub-theme.

\section{Understanding of sexual health and rights}

AGYW had a reasonable understanding of HIV: identifying how it is spread, life-long implications of diagnosis and the importance of medication adherence. Several key informants identified misconceptions about sexual health held by AGYW.

"But they are fed the information like if you use a condom, it will get stuck inside you, you understand." Community Support Officer 1.

Key informants stated that lack of education on SRHR was a reason for misconceptions. Many key informants believed that AGYW underutilized healthcare services because they were unaware of them or what they offered.

"...they don't keep informing the community of the availability of these services and the fact that Wak- iso is a peri-urban district, people settle and people go away, people settle and people go away. So the people who come in tend to miss the services thinking they are not available." District Leader 1.

Key informants were able to name some SRHR. AGYW articulated their right to consent to sexual intimacy, access health services and accept healthcare. Key informants and stakeholders felt AGYW lacked information on how to redress their rights if violated, which was borne out by testimony from AGYW suggesting they were unsure where to go if their rights were violated.

"they can get justice, but they haven't got guidance. They even say, am pregnant and am 13 years but if they are going to imprison [my partner], I should also be imprisoned. They don't understand that we are helping them in their lives to save them and also from diseases." Number 2, Focus Group 4.

\section{Sources of information}

A wide range of sources provided information about SRHR for stakeholders and key informants, for example training workshops and visiting lawyers. However, government restrictions on reproductive health education were seen as a significant barrier for AGYW.

"They have the right but our government and leaders like the religious leaders currently don't accept or allow these young girls to know about some health issues for example: reproductive health." Community Support Officer 2.

Official means of disseminating information were through radio programs and fliers/posters in English. Some stakeholders noted that printing information in English was not helpful to those who could not read or speak English.

AGYW identified their peers and community-based organisations as predominant informal information sources. Parents were often seen as barriers to understanding: withholding reproductive health information. Stakeholders described parents as unsupportive of family planning and lacking openness with their children about sexual health.

\footnotetext{
"There are parents that don't believe in family planning. They come and say, my child has started taking medication. It's also a problem especially because the parents also don't know about the importance of family planning" Number 4, Focus Group 4.

"But most parents keep things secret from their children and we don't tell them what is going on in the world." Number 5, Focus Group 3.
} 
Table 2 Themes and sub-themes identified

Theme

Understanding of Sexual Health including sexually transmitted infections and HIV

Understanding of Sexual and Reproductive Health and Rights (SRHR)

Sources of support

Experience of healthcare

Age, maturity and legal age

Violations of rights and context

Barriers to justice

Role of parents

Services available
Sub-theme

Myths and misconceptions

Knowledge of HIV among adolescent girls and young women (AGWY)

Barriers to education provision

Understanding of consent

Understanding of health and rights

Lack of knowledge about SRHR

Lack of knowledge preventing redress of rights

Lack of knowledge as a barrier to healthcare

Understanding of SRHR by stakeholders

Sources of knowledge for AGWY

Sources of knowledge for stakeholders

Support whilst menstruating or sick

Disintegration of family system of support

Role of peers

Source of support in case of harassment

Where to go for justice

Respect needed to improve healthcare

Positive experience of healthcare

Needs unrecognised among AGWY

Different treatment if poor

Use of non-traditional medicine due to fear or cost

Lack of resources or medications

Lack of psychological support

Poor service at hospital

Age at maturity

Being treated differently due to age

Stigma due to age

Education needed to support young people

People with money are treated differently

Attempted corruption

Violations within healthcare

Breach of confidentiality

Stigma associated with violation

Normalisation of sexual assault

Taking advantage of AGYW

Poverty as a driver for rights violations

Power imbalance as a driver for rights violations

Barrier to justice Prioritising reputation

Barrier to justice: Cost/corruption

Experiences of corruption

Barrier to justice: Stigma

Health professionals not testifying following rape

Threats from violators

Concern from victim they will be left without support

Police not doing their job properly

Only school attendees taken seriously

Parents forcing child marriage

Parents do not believe in family planning

Parents not open with children

Belief that children will copy parents' behaviours

Home environment as a driver for violation

Money as a driver for child marriage

Services available for HIV

Services available from interviewees

Traditional healers 
Table 2 (continued)

\begin{tabular}{|c|c|}
\hline Theme & Sub-theme \\
\hline Barriers to healthcare access & $\begin{array}{l}\text { Lack of husband's presence as a barrier to access } \\
\text { Fear as a barrier to healthcare } \\
\text { Distance as a barrier to healthcare } \\
\text { Stigma as a barrier to access } \\
\text { Husband as barrier to access } \\
\text { Parents as a barrier to access } \\
\text { Cost as a barrier to access } \\
\text { Language as a barrier } \\
\text { Rumours as a barrier to care }\end{array}$ \\
\hline Consequences of pregnancy & $\begin{array}{l}\text { Thrown out due to pregnancy } \\
\text { School dropout due to pregnancy }\end{array}$ \\
\hline Drivers for violations & $\begin{array}{l}\text { Alcohol and drugs as driver for violations } \\
\text { Belief that AGWY dressed inappropriately } \\
\text { Money as a driver for exploitation }\end{array}$ \\
\hline Redress of rights and challenges & $\begin{array}{l}\text { Informal redress of rights } \\
\text { Delay in redress } \\
\text { Length of sentence felt to be too short }\end{array}$ \\
\hline Sources of information regarding SRHR and services and areas for improvement / challenge & $\begin{array}{l}\text { How AGWY know about service availability } \\
\text { Need to educate boys as well as girls } \\
\text { Misconceptions among stakeholders } \\
\text { Resistance to learning among AGYW } \\
\text { Slum context for learning } \\
\text { Feelings that AGYW will not do as told } \\
\text { Need for education } \\
\text { Need to advertise services more }\end{array}$ \\
\hline Changes needed to allow redress of rights & $\begin{array}{l}\text { Need for empowerment } \\
\text { Government needs to change policy/law }\end{array}$ \\
\hline Suggestions for services & $\begin{array}{l}\text { Training for stakeholders } \\
\text { More funding } \\
\text { Stop corruption } \\
\text { Increase service availability } \\
\text { Empower women }\end{array}$ \\
\hline
\end{tabular}

\section{Experience of and barriers to healthcare}

Nearly all participants stated that local healthcare services lacked resources and medications. AGYW were therefore asked to pay for healthcare: from fee-forservice clinics to essential medications. For many, the financial burden was too high. Combined with fear and stigma, some participants stated that AGYW often resort to using unregulated and traditional medicine.

"...when I reach the pharmacy where am to buy the drugs from, the drugs are 30,000ugx and I only have 10,000ugx in my bag, so I find that medication too expensive. In that case, I will just go and pluck some "omululuza" and "kamunye" and I drink because it is the cheaper option that will help me." Number 10, Focus Group 5.

"They fear if they get a problem may be they want to abort, they can use these herbs and someone calls you and says this one is here dying, they say she has taken herbs." Community Support Officer 3.

Stories of poor healthcare and stigma associated with sexual health issues were common reasons for AGYW not to utilize services. Many AGYW felt they were treated differently because they were young and poor, and those in duty-bearer positions did not listen to their needs. For AGYW accessing healthcare, perceived lack of respect caused them to shy away from further healthcare. Some AGYW recalled positive healthcare experiences.

"I was given a lot of care where I gave birth from even when I hadn't paid money but that was in the [name omitted] government hospital." Number 10, Focus Group 2.

Some AGYW were denied healthcare access when visiting without a husband present. A key informant stated husbands often prevented their wives from accessing family planning services.

AGYW and key informants stated that despite the periurban environment, travel distance and costs were significant barriers to healthcare.

".... the distance is long and it is not like everyone can walk there or has the money..." Number 10, Focus Group 1. 


\section{Violations of rights}

Most participants specified that money and poverty played a significant role in the violation of AGYW's rights. Participants recalled stories of desperate family members for whom money was a driver for them facilitating their daughters to engage in underage sex and child marriage. However, parents' actions were not always described as seeking monetary gain. A local leader noted that parents forced their children to marry because it mirrored their own experience.

"...our problem is with the parents who force their children to get married fast mainly because the parents too got married early." Number 5, Focus Group 4.

AGYW also described experiences where perpetrators with money were treated differently, and a perpetrator's word was considered more credible than the word of assaulted AGYW. Other AGWY described experiences of attempted corruption of their rights for money.

"My uncle came home and he was kind of forcing me to accept money from him which was 500,000 shs and placed it on the table asking me to get the money and testify in court saying I wanted what happened to me." Number 4, Focus Group 2.

Many AGYW described guardians and duty-bearers violating their rights. This was echoed by stakeholders and included confidentiality breaches: from teachers to health workers.

"What has brought the biggest issue is health worker, they don't keep confidentiality. So people will not go to see them if they don't keep confidentiality." Number 7, Focus Group 4.

Key informants noted that sexual assault violations were normalized over a certain age. Some participants stated that AGYW are taken advantage of when trying to better their education or obtain jobs. High alcohol and drug use amongst men were named as underlying causes of domestic violence towards women.

"Sexual domestic violence is high in areas like this. For us men, the rate of drinking alcohol and drug abuse-you know what these result into. When they go back home, they harass women, because of poverty and other things. So our sisters have got problems because domestic violence is high and rape." Unknown Number, Focus Group 3.
Barriers to justice and redress of rights violations

Many stakeholders noted that while official channels existed for women to redress their rights, cases were often informally handled between families. These 'community courts' left little support for women involved.

\footnotetext{
"The other challenge that we have is that parents also always negotiate with the people that rape their children and we find ourselves in situations where cases are settled between families without consideration of the challenges that the survivor is going through or even worse still the diseases she may contract from such experiences." Number 5, Focus Group 4.
}

Even when attempting to use formal channels of justice, several AGYW experienced the prioritizing of other's reputation over their right to justice. Guardians in the home, education, and healthcare environment suppressed their rights due to appearances and to save perpetrators from jail.

"But when I tried to tell the owner of the school, he told me to leave that alone and kept silent. [He said] "The good thing you are soon finishing senior 4 and you leave the school, leave that alone, because if you report, you are going to tarnish the school's reputation."” Number 4, Focus Group 1.

"But when she told the person she stays with, that is her grandmother, the mother of her uncle, she asked one thing, "Do you want my son to be arrested?" so after they had raped her, she was in pain, but because her grandmother doesn't want her son to be arrested she didn't get her." Number 10, Focus Group 1.

AGYW sometimes choose to live without justice because they fear they will be left without support.

"So someone may not get justice because the man used her and that if the man is arrested, she may not get supports and there will be no one to support her. So it ends that it is like they have not got justice because she wants to find a way of ensuring the man looks after her." Number 9, Focus Group 3.

Key informants identified stigma towards AGYW who experienced violations, and AGYW felt stigmatised when pregnant.

"Men stigmatizing us throwing comments such as look at her she gave birth at a young age look at her legs those are the comments they throw at us." Number 4, Focus Group 2. 
Stigma was related to experiencing violations and the act of redressing it. Some participants stated that where violations were reported, the victim endured further discrimination and shame. The potential for additional stigma associated with reporting violations presented a significant barrier.

"Then the shame that is attached to the person who had been violated, oh dear, society will be like "So she thought that reporting will help?" Everywhere she will pass, she will be despised the more." Community Support Officer 4.

An individual's status in terms of money, age, and education greatly influenced whether a reported violation was believed or taken seriously. Cost and corruption were a common theme in preventing justice, particularly regarding police involvement. Many participants stated they felt the police were not effective and were open to corruption.

"Our side at the police, our mother had 100,000 ugx but she told them she had 50,000ugx, then they agrees to come and arrest the person. But we waited for them and they didn't show. When we went back, they told us we must add more money because what we had given them was less/little, so we abandoned the case." Number 6, Focus Group 1.

Health professionals were seen as reluctant to testify or support victims coming forward.

\section{Suggestions for change}

Many participants suggested that further education would empower AGYW to speak up against violations. Also mentioned was the need to educate other stakeholders, members of the community and government officials, as misconceptions were evident at all levels. One participant suggested that SRHR education should extend to boys and men given the importance of their role in ensuring women achieve their SRHR.

"So I think the other challenge is sexual and reproductive health rights being looked at as exclusively for girls, so the boys will always do whatever they want thinking that this is only for girls, which to me is something the society needs to come out strongly to educate the male youths." Community Support Officer 4.

One service provider, however, felt that education may be wasted on AGYW. They felt a divide between adults and the younger generation and suggested that the younger generation resisted advice from elders.

"Most don't want to be sensitized. In that even though you organize a training, they do not attend and yet they would have been of use to them in learning and understanding if there is any chance of an issue like this happening in the future and it is in these trainings where they would get knowledge on what to do in case the need arises." Number 6, Focus Group 5.

According to key informants and stakeholders, there may be little difference until the laws are changed to align with AGYW's needs even with increased education.

\begin{abstract}
"They [young women] may want to acquire post abortion or abortion services but it's against the law so they don't, maybe some of these cases end up into death." Community Support Officer 5.

"For example in schools the information we give them according to the Ministry of Education and Sports, it is less to what they need They tell us not to talk about abortion but this is what the girls are facing and they need this information and service provision somehow but they can't access. They need the knowledge but you still can't give because it's against the law." Community Support Officer 5.
\end{abstract}

Another key informant suggested that more resources and funding specifically for adolescent health would improve service delivery.

"More funding should be directed towards Adolescent health because we really don't have a vote for adolescent health as a standalone. We are running... integrating it with other services and we run on other service now like HIV and ride on them." District Leader 2.

Many stakeholders suggested that fighting corruption would make a difference to overall SRHR service delivery. One participant felt sentences for perpetrators were too light, and did not act as significant disincentives to repeat offence.

"Can I also add that the police is not doing us enough justice because ideally whoever violates should be handled by a strong law, people don't understand that once you violate a girl's or boy's sexual rights you are ruining this person for good. Someone found guilty takes a very light sentence and goes and violates another one, they bring them back and it's the same light sentence." Community Support Officer 4. 


\section{Discussion}

Themes arising in the data describe SRHR gaps and violations as they relate to AGYW living in urban slums in Uganda, and suggest areas amenable to intervention based on HRBA principles.

Analysis revealed that poverty remains a common driver of SRHR violations: reducing healthcare access, rendering treatments unaffordable, exposing vulnerabilities in the lives of AGYW and their families, and preventing justice by tolerating environments where corruption, particularly by police, is pervasive. Despite these challenges, there appeared ample opportunity for promoting empowerment through education, as recommended by the World Health Organisation [21]. With knowledge gaps identified, raising awareness amongst AGYW, stakeholders and the wider community could address misconceptions, encourage participation and set the stage for stronger accountability mechanisms.

Our study is the first to outline the challenges faced by AGYW in achieving SRHR in a slum setting in Uganda. Indeed, a recent scoping review identified no qualitative evidence regarding sexual and reproductive health challenges among young people living in slums in Uganda, and limited qualitative evidence in the rest of Sub-Saharan Africa [17]. A cross-sectional study undertaken among 13-24 year olds in Makindye and Nakawa Divisions of Kampala identified sexual assault as a common issue, in keeping with our findings [19].

Initiatives like specifically criminalizing gender-based violence, as enacted in Uganda in 2010 [22], can be important in the journey towards supporting AGYW to achieve SRHR. However, as data from this study show, legislation alone cannot solve the problem. Other qualitative and implementation studies have utilized bottomup HRBA to affect change. Methods focusing on legal empowerment for health promotion have been applied to HIV [23], while community-based awareness campaigns have demonstrated attitude shifts towards young mothers through empowerment and income generation [24]. These interventions highlight the strength in strategically incorporating the wider community when addressing SRHR issues.

This study encouraged open discussions of experiences and opinions amongst peers. Critical to the process of developing HRBAs [11], this information provides a current assessment and analysis of rights, upon which interventions can be tailored to address the specific causes of non-realisation of rights for these AGYW, thus avoiding carbon copying of methods elsewhere and strengthening the likelihood of sustainability [25].

The UNFPA suggests that empowerment comes from not only knowing your rights but also knowing that those in power are aware, duty-bound, and actively supporting these rights [8]. An additional strength of this study is in establishing partnerships and networking stakeholders and duty-bearers in their awareness and commitment to protection of AGYW's SRHR. The interviews with key informants brought additional depth, painting a wider picture of the structural causes effecting the realisation of AGYW's SRHR.

This study was conducted in just two slums in a single country and not all findings will be generalisable to other contexts. Other limitations include the selfselecting nature of participants, particularly AGYW who were under 18. Requiring parents' consent may have limited participation to those whose parents were open and might not represent experiences of AGYW whose parents held different attitudes. However, this was likely overcome with the inclusion of AGYW over 18; in fact, parental beliefs and behaviour as rights violations and barriers to justice were identified. The participant threshold was predetermined based on available time and resources, and on participants' roles and affiliations within the slums. Further studies in urban areas allowing for more participants would help achieve data saturation.

\section{Conclusions}

This study has identified important barriers and facilitators for AGYW to achieve their SRHR in an urban slum context. Barriers identified included stigma towards pregnant teenagers, cost preventing healthcare access, and family, police and school sometimes acting as barriers to the redress of rights. Facilitators identified included education to address misconceptions and improved accountability mechanisms. The knowledge obtained from this study and the connections established will be used to develop an intervention based on legal empowerment and social accountability approaches. Grounded in human rights norms, the resulting intervention could increase awareness, empower and promote agency in AGYW living in slums [25]. The need for such an intervention was evident in discussions with key informants, many of whom actively sought advice regarding rightsbased implementation from the research team. While this study was conducted in Uganda, worldwide reports suggest that many countries are struggling with similar misinformation, resource constraints and communitydriven stigmas [2], suggesting that a resulting intervention may be relevant to other contexts too. Through awareness and continued engagement, targeted interventions for the realisation of AGYW's SRHR can address underlying causes and positively shift attitudes for the promotion of health. 


\section{Abbreviations}

AGYW: Adolescent girls and young women; SRHR: Sexual and reproductive health and rights; HRBA: Human rights-based approach; CEHURD: Center for health, human rights and development, Uganda; LMIC: Low and middleincome countries; HIV: Human immunodeficiency virus.

\section{Supplementary Information}

The online version contains supplementary material available at https://doi. org/10.1186/s12978-021-01174-z.

Additional file 1. Is the topic guide for interviews.

Additional file 2. Is the topic guide for stakeholder focus groups.

Additional file 3. Is the topic guide for AGYW focus groups.

Additional file 4. Is a Table outlining themes and sub-themes identified with illustrative quotes.

\section{Acknowledgements}

We would like to thank the participants that contributed to this study.

\section{Authors' contributions}

$\mathrm{OO}$ and SS conceptualised the study. JN, DAN, CB, CO, FS, JN and MK contributed to data collection, translation and transcription. MM led data analysis. Data were coded by DAN, JN, FA, MM and EB-M with coding decisions discussed with OO. EB-M and MM drafted the manuscript. OO provided supervisory support and oversaw the study. The final manuscript was approved by all authors. All authors read and approved the final manuscript.

\section{Funding}

The project was funded by the University of Warwick Global Challenges Research Fund Catalyst Grant (GCRF). OO is supported by the National Institute for Health Research (NIHR) Global Health Research Unit on Improving Health in Slums. The views expressed in this publication are those of the author(s) and not necessarily those of the NIHR or the UK Department of Health and Social Care.

\section{Availability of data and materials}

The anonymised datasets used and/or analysed during the current study are available from the corresponding author on reasonable request.

\section{Declarations}

\section{Ethics approval and consent to participate}

Ethical approval was obtained from the University of Warwick's Biomedical and Scientific Research Ethics Sub-Committee (REGO-2019-236) and the School of Biomedical Sciences Higher Degrees Research Ethics Committee, Uganda. Informed written consent was obtained from all participants in interviews and focus group.

\section{Consent for publication}

All included data are anonymised.

\section{Competing interests}

None declared.

\section{Author details}

${ }^{1}$ University of Warwick Medical School, Medical School Building, Coventry, UK. ${ }^{2}$ Center for Health, Human Rights and Development (CEHURD), Kampala, Uganda. ${ }^{3}$ University of Warwick, Law School, Coventry, UK

Received: 23 October 2020 Accepted: 6 June 2021

Published online: 12 June 2021

\section{References}

1. UNFPA. Sexual \& reproductive health [Internet]. UNFPA. 2020. https:// www.unfpa.org/sexual-reproductive-health.

2. UNFPA. Sexual and reproductive health and rights: an essential element of universal health coverage. UNFPA. 2019.

3. Temmerman M, Khosla R, Say L. Sexual and reproductive health and rights: a global development, health, and human rights priority. Lancet 2014;384(9941):e30-1.

4. Garcia-Moreno C, Jansen HAFM, Ellsberg M, Heise L, Watts C. WHO Multi-Country Study on Women's Health and Domestic Violence Against Women: Report on the First Results. World Health Organization. 2005.

5. Bustreo F, Hunt P, Gruskin S, Eide A, McGoey L, Rao S, et al. Women's and Children's Health: Evidence of Impact of Human Rights [Internet]. Geneva; 2013. http://apps.who.int/iris/bitstream/10665/84203/1/97892 41505420 eng.pdf.

6. Starrs AM, Ezeh AC, Barker G, Basu A, Bertrand JT, Blum R, et al. Accelerate progress - sexual and reproductive health and rights for all: report of the Guttmacher-Lancet Commission. Lancet. 2018:391(10140):2642-92.

7. United Nations. Transforming Our World: The 2030 Agenda For Sustainable Development. 2015.

8. UNFPA. The Human Rights-Based Approach [Internet]. 2014 [cited 2019 Dec 19]. https://www.unfpa.org/human-rights-based-approach.

9. George AS, Branchini C, Portela A. Do interventions that promote awareness of rights increase use of maternity care services? A systematic review. PLoS ONE. 2015;10(10):1-15. https://doi.org/10.1371/journ al.pone.0138116

10. Stangl AL, Singh D, Windle $M$, Sievwright $K$, Footer $K$, lovita A, et al. A systematic review of selected human rights programs to improve HIVrelated outcomes from 2003 to 2015: what do we know? BMC Infect Dis. 2019;19(1):209.

11. The Human Rights-Based Approach to Development Co-operationTowards a Common Understanding among UN Agencies. Integrating Human Rights into Development, Second Edition. 2013. 245-250 p.

12. Thomas R, Kuruvilla $S$, Hinton R, Jensen SLB, Magar V, Bustreo F. Assessing the impact of a human rights-based approach across a spectrum of change for women's, children's, and adolescents' health. Heal Hum Rights J. 2015;17(2):11-20.

13. World Population Prospects 2019 [Internet]. UN Department of Economic and Social Affairs. 2019 [cited 2020 Oct 9]. https://population. un.org/wpp/.

14. Patton GC, Sawyer SM, Santelli JS, Ross DA, Afifi R, Allen NB, et al. Our future: a Lancet commission on adolescent health and wellbeing. Lancet. 2016;387(10036):2423-78.

15. Uganda Bureau of Statistics (UBOS) and ICF. Uganda Demographic and Health Survey 2016. Kampala, Uganda and Rockville, Maryland; 2018.

16. Stackpool-Moore L, Bajpai D, Caswell G, Crone T, Dewar F, Gray G, et al. Linking sexual and reproductive health and rights and HIV services for young people: the link up project. J Adolesc Heal. 2017;60(2):S3-6.

17. Wado YD, Bangha M, Kabiru CW, Feyissa GT. Nature of, and responses to key sexual and reproductive health challenges for adolescents in urban slums in sub-Saharan Africa: a scoping review. Reprod Health. 2020;17(1):1-14.

18. McGranahan M, Nakyeyune J, Baguma C, Musisi N, Nsibirwa D, Sekalala $S$, et al. Rights based approaches to sexual and reproductive health in low and middle-income countries: A systematic review. PLoS One. 2021;16(4):e0250976. https://doi.org/10.1371/journal.pone.0250976.

19. Renzaho AMN, Kamara JK, Georgeou N, Kamanga G. Sexual, reproductive health needs, and rights of young people in Slum Areas of Kampala, Uganda: a cross sectional study. PLOS ONE. 2017;12(1):1-21.

20. O'Brien BC, Harris IB, Beckman TJ, Reed DA, Cook DA. Standards for reporting qualitative research: a synthesis of recommendations. Acad Med. 2014:89(9):1245-51. 
21. World Health Organization. WHO recommendations on adolescent sexual and reproductive health and rights [Internet]. Geneva; 2018. https://apps.who.int/iris/bitstream/handle/10665/275374/9789241514 606-eng.pdf?ua $=1$.

22. Domestic Violence Act, 2010. UPPC, Entebbe, by Order of the Government; 2010.

23. Auerbach J. Transforming social structures and environments to help in HIV prevention. Health Aff (Millwood). 2009;28(6):1655-65.

24. Leerlooijer JN, Bos AE, Ruiter RA, Van Reeuwijk MA, Rijsdijk LE, Nshakira $N$, et al. Qualitative evaluation of the Teenage Mothers Project in
Uganda: a community-based empowerment intervention for unmarried teenage mothers. BMC Public Health. 2013;13(1):1-15.

25. Joshi A. Legal empowerment and social accountability: complementary strategies toward rights-based development in health? World Dev. 2017;99:160-72.

\section{Publisher's Note}

Springer Nature remains neutral with regard to jurisdictional claims in published maps and institutional affiliations.
Ready to submit your research? Choose BMC and benefit from:

- fast, convenient online submission

- thorough peer review by experienced researchers in your field

- rapid publication on acceptance

- support for research data, including large and complex data types

- gold Open Access which fosters wider collaboration and increased citations

- maximum visibility for your research: over $100 \mathrm{M}$ website views per year

At BMC, research is always in progress.

Learn more biomedcentral.com/submissions 